\title{
Futurismo arcaizante: descolonización y anarcofeminismo en De cuando en cuando Saturnina
}

\author{
Hannah A. Burdette \\ Univestity of Pittsburgh
}

\begin{abstract}
Drawing on the description of De cuando en cuando Saturnina by Alison Spedding as "native anarco-feminist science fiction" announced on the back cover of its first edition (2004), this article proposes an interconnected reading of these four axes (futurism, Aymara logic, anarchism, and feminism). I argue that the structure of this "oral history of the future" conveys a critical resolve to avoid positing the reinstatement of Qullasuyu as the utopic horizon of an idyllic society, while the text as a whole remains committed to a radical decolonization of Bolivia anchored in an autonomous cultural grammar. In this sense, the novel offers a critical vision not only of the coloniality that Aymara culture has endured but also of certain challenges internal to Aymara society itself, particularly in regards to gender hierarchy.
\end{abstract}

Keywords

Anarchism, Aymara Logic, Decolonization, Feminism, Science Fiction

\section{Resumen}

Partiendo de la descripción de la novela De cuando en cuando Saturnina (Alison Spedding, 2004) como "ciencia ficción originaria anarco-feminista" declarada en la contratapa de la primera edición, el presente trabajo 
propone una lectura entrecruzada de estos cuatro ejes (futurismo, lógica aymara, anarquismo y feminismo). Leo en la estructura de la "historia oral del futuro" una voluntad crítica que rehúye cualquier tentación de ver la reinstauración de Qullasuyu como horizonte utópico de una sociedad idílica, pero que al mismo tiempo apuesta a una descolonización radical de Bolivia anclada en una gramática cultural autónoma y propia. Así, la novela despliega una visión crítica no sólo de la colonialidad a la que ha estado sometida la cultura aymara sino también de ésta misma y de sus desafíos internos, particularmente en relación a jerarquías de género.

\section{Palabras Claves}

Anarquismo, Ciencia Ficción, Descolonización, Feminismo, Lógica Aymara

\section{De cuando en cuando Saturnina (Saturnina from time to time) Una historia oral del futuro}

Alison Spedding Pallet (La Paz: Editorial Mama Huaco, 2004)

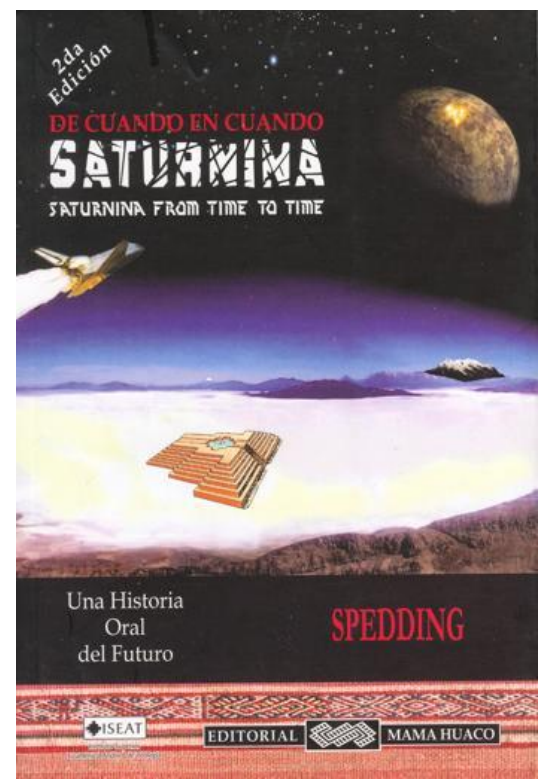

Portada de la segunda edición (2010) 
La Bolivia del 2011 se encuentra en un punto de encrucijada. Parecería estar, al decir de tantos, en tiempos de pachakuti, de transformación radical del tiempo-espacio, a la entrada de otro mundo aún por determinarse. Con una nueva constitución fundamentada en preceptos ético-sociales propiamente andinos como el suma qamaña, un presidente elegido con más del $62 \%$ del voto ciudadano y la instauración oficial (por lo menos en el plano discursivo) del Estado plurinacional como alternativa al modelo monolítico neocolonial, es evidente que se están abriendo caminos hacia otro tipo de organización social, política, económica y filosófica. No obstante, el rumbo que podría o debería tomar la Bolivia de hoy todavía no está claro. ¿Se logrará realmente un cambio radical, rompiendo definitivamente con la colonialidad del poder, del saber y del ser, o se producirá más bien una transposición de las dinámicas de poder hacia otras zonas de opresión y conflicto? ¿Se mantendrá el esqueleto básico del estado-nación al estilo moderno, occidental y neoliberal, o se instaurará una forma de gobernabilidad radicalmente diferente basada en una estructuración sociopolítica propiamente andina? Y si se da el pachakuti de esta forma, ¿qué desafíos y dificultades se introducirían desde dentro de la comunidad del ayllu, tanto para su constitución interior como para su inserción exitosa y liberada en el mundo globalizado del siglo XXI?

La novela De cuando en cuando Saturnina. Una historia oral del futuro, publicada el año 2004 por la antropóloga y escritora inglesa residente en Bolivia, Alison Spedding, recurre al espacio imaginario e hipotético de la ciencia ficción para explorar éstas y otras cuestiones. Situada en un momento del futuro alrededor del año 2086, esta "historia oral del futuro" presenta una serie de reflexiones, retrospecciones, diálogos e incluso conversaciones con muertos, que en su conjunto relatan la historia de medio siglo de descolonización después de la expulsión de los q'aras del territorio que fue Bolivia. Desde el 2022, la ex Bolivia, ahora Qullasuyu Marka, es una sociedad sin Estado: carente de presidente, diputados, ministros, ejército y policía, la denominada "Zona Liberada" se rige más bien por una suerte de ley común basada en la estructura de los ayllus, liderada al nivel local y regional por un conjunto de gremios y autoridades rotativas. Después de una guerra cruenta y el eventual triunfo de la revolución indianista, la nuevamente formada Qullasuyu Marka ha decidido encerrarse y aislarse del mundo para llevar a cabo un proceso de reconstrucción interna y refortalecimiento cultural y espiritual, cerrando sus fronteras y soportando un bloqueo económico por parte de los "Estados Jodidos" al ser calificada de Estado racista y expansionista. Las únicas personas libres de entrar y salir de la Zona son los miembros del Space Engineering and Applied Astronomy Corporation 
[Corporación de Ingeniería Espacial y Astronomía Aplicada] conocido como el Sindicato, una "organización de profesionales en ingeniería de programas de navegación espacial procedentes del Qullasuyu, reconocida mundialmente por la alta calidad de sus servicios" (v). ${ }^{1}$ A la misma pertenece Saturnina Mamani Guarache (alias la Satuka), protagonista de la novela, hacktivista lesbiana, e integrante del Comando Flora Tristán un grupo anarcofeminista radical basado en el Bajo Perú ${ }^{2}-$ que no sólo comete actos de terrorismo anticolonial fuera de la Zona, sino que también desafía la autoridad patriarcal de los amawt'as dentro de aquélla, una transgresión que paga encerrada por un tiempo en la única cárcel de la Zona.

Al desplazar su reflexión sobre los procesos políticos en Bolivia hacia un futuro alejado (2070-2086) pero con referencia a una rebelión masiva y tremenda correspondiente a un futuro mucho más cercano (2022), Spedding construye una narrativa fragmentada y compleja que se mueve en un espacio de sesenta años de historia futura a través de los recuerdos de las protagonistas, y que está anclada simultáneamente en una concepción aymara del tiempo-espacio y en una visión crítica e imaginativa de la Bolivia actual. Partiendo de la descripción de la novela como "ciencia ficción originaria anarcofeminista" declarada en la contratapa de la primera edición (2004), el presente trabajo propone una lectura entrecruzada de estos cuatro ejes (futurismo, lógica aymara, anarquismo y feminismo). Leo en la estructura de la "historia oral del futuro" una voluntad crítica que rehúye cualquier tentación de ver la reinstauración del Qullasuyu como el horizonte utópico de una sociedad perfectamente igualitaria e idílica, pero que al mismo tiempo apuesta a una descolonización radical de Bolivia en base a una gramática cultural autónoma y propia. Así, la novela despliega una visión crítica no sólo de la colonialidad a la que ha estado sometida la cultura aymara, sino también de la cultura aymara misma y sus desafíos internos, con el efecto de brindar una reflexión cariñosa y comprometida sobre los retos, la violencia y las contradicciones propias del proceso de descolonización en Bolivia.

${ }^{1}$ En este trabajo utilizo la primera edición de la novela, publicada el 2004.

2 En contraste, el Alto Perú correspondería a la región de Puno, que en el año 2025 decidió integrarse al Qullasuyu Marka y se separó políticamente del resto de Perú. 


\section{Destejiendo el orden temporal histórico}

Si la Satuka es famosa dentro del Sindicato por su destreza de programación y agilidad de navegación, Spedding también pilotea hábilmente la narración del libro a través del tiempo-espacio de los sesenta años de liberación del Qullasuyu, saltando constantemente entre varias instancias de pasado y futuro que se confunden en una red temporal intrincada que rompe definitivamente con cualquier concepción lineal de la historia. Como explica el "manual para la usuaria",

El texto que sigue consiste [...] de una serie de relatos y/o conversaciones, más que entrevistas propiamente dichas, conformando en total treinta y cuatro capítulos de extensión variable. Fueron realizadas con diferentes personas en diferentes ocasiones. Por tanto, no conforman un sólo relato lineal, y es posible leerlos en diferentes órdenes, aparte del orden narrativo general escogido por los recopiladores (vii).

De este modo, el orden narrativo del texto se reconoce como abiertamente arbitrario, y las distintas posibilidades de lectura que plantean los "editores" ficticios - guiadas por el orden de los acontecimientos centrales, designado en el "Manual para la usuaria" con la letra T y un número; por el orden de los acontecimientos del "pasado" (P); o incluso por el orden en que fueron relatadas las memorias (Q) apuntan hacia una estructura narrativa basada en la lógica de la memoria y la oralidad simultáneamente anclada en una concepción andina del tiempo. Así, la autora opta por señalar posibles caminos a la vez de dejar la ruta abierta a que la lectora "navegue" como desee (viii).

Se trata, entonces, de varias capas de temporalidades y niveles intercalados de retrospección que intencionadamente rehúyen una cronicidad historicista, en una técnica narrativa que explícita, aunque irónicamente, se conecta con el modelo de la rayuela de Cortázar. De este modo, Spedding enmarca la redacción del libro alrededor del año 2086, combinando una imaginación futurística con una estructuración narrativa retrospectiva en una mirada que Anabel Gutiérrez León ha denominado "retro-futurística". La novela "comienza", por decirlo así, en un momento lejano del futuro y va acercándose a nosotros en el tiempo a través de las memorias de las protagonistas, sin tocar nunca el momento de nuestro presente (o el momento en el que se escribió y publicó el libro, hace ya varios años). La Liberación, en este sentido, se proyecta en la lectura como un evento posible perteneciente a un futuro cercano, mientras que para las protagonistas ya ha pasado más de medio siglo desde la incidencia de este acontecimiento. El efecto que esto 
produce es el de mirar atrás mirando al futuro: la escritora nos hace ver un futuro hipotético, mientras que las narradoras miran desde nuestro futuro hacia su pasado (que es todavía nuestro futuro).

Al construir esta "historia oral del futuro", entonces, Spedding claramente nos está brindando una forma alternativa de construir la historia basada en la oralidad y por lo tanto necesariamente despegada de cualquier comprensión lineal del tiempo-espacio. Así se viabiliza y se activa, dentro del formato novela, la noción andina de nayrapacha: "pasado, pero no cualquier visión de pasado; más bien, 'pasado-comofuturo' [...] Un pasado capaz de renovar el futuro, de revertir la situación vivida" (Rivera Cusicanqui 44). Se trata, en otras palabras, de una exploración narrativa de la forma andina de "vivir mirando desde el pasado hacia el futuro" (Spedding 87), coincidente con una estrategia crítica que utiliza el futuro como reflejo transfigurado del presente. Como observa Raquel Alfaro en una reseña de la novela, "Adecuando la ciencia ficción, género nacido en occidente y que expresa la visión histórica hegemónica aunque de manera negativa (el avance conduce al apocalipsis), la escritora logra [...] desordenar la historia futura de modo tal que permita el ejercicio de una crítica oblicua a la situación plurinacional contemporánea" (347). Significativamente, no es a través de la historia oficial y nacional de Qullasuyu Marka que se accede a esta mirada, sino por medio de una colección de recopilaciones orales que reparten la perspectiva exclusivamente femenina de una lesbiana subversiva, su pareja y su abuela difunta. "[Y]o mey admirado de cómo se confecciona la historia - observa la Satuka-. Ahora dicen que la historia que enseñaban antes era puras mentiras de q'aras pero ahora sería mentiras de amawt'as, diría yo" (55).

No es por casualidad que el resultado de este destejido de la temporalidad lineal se asemeja a lo que el historiador subalternista Ranajit Guha, en un ensayo titulado "The Small Voice of History" [La pequeña voz de la historia], ${ }^{3}$ imagina como una posible narración historiográfica no estatista. Al identificar la historiografía tradicional como una producción "estatista", tiene la intención de manifestar una lógica subyacente inescapablemente pegada a la formación del Estado. Lo que la historiografía subalternista debería hacer, según él, es "[to] push the logic of its revision to a point where the very idea of instrumentality, the last refuge of elitism, will be interrogated and re-

${ }^{3}$ Todas las traducciones del inglés al español pertenecen al trabajo editorial de la Revista de Estudios Bolivianos. 
assessed [empujar esa lógica hasta un punto en el que la idea misma de instrumentalidad, la última figura del elitismo, sea interrogada y reevaluada] (12)." Es importante notar que esta reflexión lleva a Guha a una discusión de carácter narratológico, que en su momento de mayor productividad plantea que la única historia capaz de subvertir el estatismo tendría también que quebrar su línea argumental, haciendo desastre de su trama. ¿Qué forma tomaría este desorden narrativo? se pregunta,

Perhaps it will force the narrative to stutter in its articulation in stead of delivering in an even flow of words; perhaps the linearity of its progress will dissolve in loops and tangles; perhaps chronology itself, the sacred cow of historiography, will be sacrificed at the altar of a capricious, quasi-Puranic time which is not ashamed of its cyclicity (12).

[Quizás forzará a la narrativa a tardamudear en su articulación en lugar de entregar un flujo coherente de palabras; quizás la linealidad de su progreso se disolverá en círculos y enredos; quizás la cronología misma, la vaca sagrada de la historiografía, será sacrificada en el altar de una época caprichosa, cuasi-puránica que no esté avergonzada de su ciclicidad].

Estas observaciones indican que el modelo narrativo o incluso historiográfico de Spedding, basado en los brincos y lapsos de la memoria como la forma más humana de experimentar el tiempo, tiene implicaciones significativas para una reflexión sobre la relación entre narrativa, estatismo, modernidad y progreso. No se trata simplemente de un juego de rayuela, de un gesto lúdico de subvertir la historicidad de las narrativas oficiales/estatales, sino también, y esto es lo interesante, de otra forma de concebir maneras de estar en el mundo y de trabajar por un cambio político con objetivos, pero sin teleología. Queda claro que la misma temporalidad narrativa de esta novela no sólo responde a una tentativa de construir una "historia oral escrita" que corresponda a nociones aymaras del tiempo-espacio, sino también a una subversión de la lógica estatista inherente al modelo historiográfico tradicional. El pasado-futuridad, en otras palabras, sirve para enfatizar una constante necesidad de cambio que desestabiliza cualquier sentimiento de haber "llegado" con la disolución del Estado. Si el tiempo es circular y no lineal, como postularía la concepción aymara de las pachas o divisiones 
temporales, ${ }^{4}$ la era posrevolucionaria posterior al q'ara timpu señala la instauración de nuevos poderes y la continuación de otros anteriores.

\section{"Anarquismo a lo andino"}

Por lo tanto convendría ahora navegar nuestra reflexión hacia la representación de esta "sociedad sin Estado" dentro de la novela en relación a formas ya existentes de organización social excluidas y subyugadas por el Estado monista neocolonial. Si bien la novela constituye una forma de exploración ficcional de las posibilidades alternativas de sociabilidad política y reglamento comunitario, esta realidad hipotética no se basa en una invención arbitraria y literaria de la autora sino en un sistema proveniente de la época colonial aún vigente y vivo hoy en día. De este modo la autora se apropia de la ciencia ficción género representativo de la posmodernidad occidental y el capitalismo tardío - como estrategia para insertarse en varios debates actuales dentro y fuera de Bolivia acerca del proceso de descolonización aymara y la posibilidad de construir un "Estado que no sea Estado" basado en el ayllu.

Se trata, en breve, de imaginar cómo sería una sociedad boliviana (o, más bien, qullasuyana) liberada del neocolonialismo y el neoliberalismo, y articulada en términos sociopolíticos alrededor de una autonomía recobrada y reinstaurada. En Dispersar el poder, Raúl Zibechi opta por leer los recientes movimientos indígenas (sobre todo el Zapatista en Chiapas, el Movimiento Pachakutik en Ecuador y las varias movilizaciones en Bolivia, desde la Guerra del Gas hasta la política del MAS), en términos de un objetivo compartido de autonomía anti-estatal. Para este

${ }^{4}$ Ver González León para un examen detallado del tiempo mitológico aymara en relación con la novela de Spedding. "A diferencia de la concepción lineal del tiempo occidental -explica González León-, en la cosmovisión aymara el tiempo es circular. Todo retorna. Así como los animales, las plantas y la naturaleza son cíclicos, las culturas también tienen un ciclo. [...] El pasado está delante porque es lo conocido, lo ya visto; en cambio el futuro, que es algo que no se ve, está detrás". En breve, se trata de tres tipos distintos de tiempo que se encuentran siempre en rotación consecutiva. "Si en el taypi se producía la unión o concentración en un centro; en el puruma se produce una división de lo que estuvo unido o era indiferenciado, una expansión hacia bordes difusos. El tercer pacha, que es el que más interesa para la lectura [de] De cuando en cuando Saturnina, es la edad del Awqa o Pachakuti. [...] Se refiere a todo aquello que es contrario, opuesto, que no puede estar junto ni coincidir, como el día y la noche o el agua y el fuego". 
pensador, tal búsqueda de autonomía puede obrar al margen del Estado o a través de él, pero el ímpetu fundamental, en los dos casos, sería una resistencia a la concepción centralizada del Estado moderno y neoliberal, donde los representantes deciden por sus electores (a favor o en contra de los intereses y el consenso de ese grupo), en contraste con un sistema en el que el representante comunitario "solamente expresa, ejecuta, lo que ha decidido su comunidad, es un transmisor" (Patzi, citado en Zibechi 158). ${ }^{5}$ Este objetivo insurgente de redistribuir el poder centralizado del Estado toma el ayllu como base de una articulación compleja de la sociedad que abarca la política, la cultura, la economía y la ética comunitaria en un sistema integral que permea todas las intersecciones de la sociabilidad popular (113). Para Félix Patzi, este modelo posibilitaría una suerte de Estado que gobierne desde abajo, en una forma de poder subalternizado equiparable al postulado zapatista de "mandar obedeciendo": "ese estado no se colocaría por encima sino por debajo de la sociedad, ejecuta las decisiones, discute las expresiones de las diferentes colectividades pero no las suplanta" (citado en Zibechi 158). Para Zibechi el Estado como tal -entendido por definición como una estructura política que ejerce poder sobre la sociedad- no existe propiamente en la lógica cultural andina, pero el suyu sí, como un conjunto grande de ayllus que se ha interpretado como un Estado que no es Estado, donde sociedad y Estado ya no constituyen dos entidades separadas y jerarquizadas, sino que "El estado es la sociedad y la sociedad es estado" (Mamani, citado en Zibechi 159).

Este recorrido por algunas perspectivas sobre el papel del Estado en el pachakuti - al cual sólo cabe aludir brevemente aquí- sugiere el complejo tejido de preguntas y discusiones a las que intenta responder nuestra autora. La novela, en breve, apuesta a la posibilidad de la descolonización y de una sociedad autónoma basada en una gramática cultural propiamente andina. Proponiendo una forma de volver al pasado caminando hacia el futuro y una concepción de progreso como un destejimiento de las estructuras coloniales de poder y la recuperación de conocimientos y prácticas ancestrales, el pachakuti en Qullasuyu deriva en lo que algunas personas de afuera (simpatizantes y admiradores de la Liberación) califican de una "utopía arcaizante". Al explicar el éxito de la labor aymara artesanal en relación al mercado internacional, Satuka afirma que "Hay los que buscan los tejidos tradicionales, fibra natural y

${ }^{5}$ Las citas de Félix Patzi que se incluyen aquí, como también la de Pablo Mamani más adelante, provienen de entrevistas personales conducidas por Raúl Zibechi y referenciadas en Dispersar el poder. 
tintes vegetales, porque en eso sí hemos progresao, o recuperado si quieres, después de la Liberación" (257-58). Más que rechazar el capitalismo y la economía de exportación, en este sentido, los qullasuyanos han sabido utilizar el mercado y la tecnología a su favor (desarrollando, por ejemplo, una especie de robot pastor) y apropiándola para sus propios fines y beneficios, en una suerte de progreso que se mueve no sólo hacia adelante sino también hacia atrás.

No obstante, quisiera argüir que la insistencia antiteleológica del relato debería prevenirnos de leerlo como una visión utópica del ayllu y del mundo aymara después del q'ara timpu. Si de verdad "Esta es la primera vez que la 'Cortina de Hierro en los Andes' se abre para dar a una mirada a un pueblo misterioso y legendario" (vi), no será para confirmar las suposiciones ni demonizadas ni idealizadas desde fuera. No es, pues, esa utopía pachamámica ${ }^{6}$ retratada "en algunos websites de soi-disant simpatizantes, todos trabajando colectivamente, abolida la propiedad privada, agricultura cien por ciento orgánica, armonía ecologista..." (126). En una conversación entre Satuka y Feliciana, una bajoperuana del Flora Tristán, se observa claramente este contraste entre la visión desde fuera y la realidad de adentro:

- ... [V]os sabes que lo que se admira desde fuera es la liberación del racismo colonial, la autosuficiencia alimentaria, la recuperación de los saberes ancestrales, la tecnología apropiada... [...] Ya también sabíamos que habían botado a los curas, los evangélicos, todo, y vos misma me has dicho el porqué de la prohibición de realizar actos rituales fuera de la Zona. Y además, es Tahuantinsuyu recuperado pero sin el Inka Rey...

-... el paraíso verde combinado con la utopía anarquista, yaa. La utopía arcaizante.

- Será ps que yo era ilusa, pero la verdad es que no imaginaba una teocracia clandestina, con sesiones de ch'amakani en vez de juicios de asesinato, y cárceles dirigidas por yatiris.'

-En combinación incómoda pero aparentemente estable con el neoliberalismo online y una economía de remesas, ¿no? (275).

La realidad de esa "sociedad sin Estado", a fin de cuentas, es mucho más esquiva de lo que parecería, y muy alejada de ideales pastoriles.

${ }^{6}$ El glosario que aparece al final de la novela define a los 'pachamámicos' como "especie de nacionalistas místicos andinos, tirando al estilo New Age pero con contenidos que ellos imaginan como auténticamente andinos" (331). 
Aunque "durante un rato realmente era verdad eso de ningún gobierno" (57), el creciente poder de los amawt'as y yatiris ha ido complejizando la posibilidad de hablar propiamente de un estado de anarquía; más bien, éste sería el horizonte de posibilidad continuo que representa la estructura del ayllu, encarnada en la novela en la lucha antiimperialista y antipatriarcalista de Saturnina y el Comando Flora Tristán.

Más que anarquía, entonces, se trata de una suerte de teocracia andina, en la que el gremio de amawt'as utiliza la plataforma de la espiritualidad para inmiscuirse en todos los aspectos de la sociedad qullasuyana:

El gremio Amawt'a supuestamente es sólo un gremio más, se ocupa del culto y del bienestar espiritual y también manejan la educación. Pero todos sabemos que el culto y la educación para ellos es bastante amplio. Se metían en todo, en un principio con un afán de extirpar el cristianismo en todas sus formas y luego decidían que la guerra era también una forma de culto, era con eso que lograron desbaratar a los Felipe Quispes y demás organizaciones armadas. Aparte del cristianismo hay libertad de culto, dicen, pero es prohibido ser layqa, hacer brujerías (108).

Los amawt'as, en muchos momentos, llegan a adquirir características de un Partido de régimen socialista, "reeducando" a los cristianos retrógradas y en casos extremos llevando a los renegados a un pico nevado para morir sacrificados por el frío. A fin de cuentas, la educación no deja de ser una herramienta disciplinaria ${ }^{7}$ y la religión una forma de homogeneización ideológica; aunque las dos instituciones se viabilicen en este contexto para un proceso de descolonización del saber y del ser, el poder continúa circulando y fortaleciéndose dentro de ellas, aunque transmutada de forma y manifestación.

Se trata, quizás, del momento de institucionalización de la insurrección, donde el contrapoder se convierte en poder, donde la anarquía vuelve a instaurarse de nuevo como un horizonte de posibilidad, más que una realidad inmediata. Pero esta constante desestabilización del poder, de hecho, viene a ser la condición necesaria de la prolongación del sistema del ayllu y su funcionamiento: la rotación constante de autoridades locales sirve precisamente para evitar que un grupo u otro se hegemonice o se vuelva dominante sobre los otros. Una tendencia a la aspiración al poder y la envidia, después de todo, no son

7 Afirma la Satuka que "la escuela es una institución disciplinaria en donde sea, bilingüe, monolingüe, el problema no radica allí. Hasta en la Zona es disciplinaria, no creas que no" (41). 
privativos del Estado occidental, ${ }^{8}$ pero es por eso, precisamente, que el ayllu dependerá de un impulso anarquista desestabilizador para sostenerse. Al decir de Zibechi,

De ese modo, la ambigüedad india, que forma parte de la radical ambigüedad del ser humano - no será resuelta eliminando uno de sus momentos extremos (objetivo jacobino de la llustración), sino surcando las procelosas aguas de la vida, inclinando el timón hacia la orilla de la emancipación, o sea hacia el no estado, sabiendo que la inercia propia de la vida-navegación nos impulsa - quizá también de modo inevitable - hacia la reconstrucción de lo instituido, el estado, la opresión... (191).

Se trata de la prolongación infinita del momento revolucionario al que tan lúcidamente invita Benjamin en sus tesis sobre la historia: un Jetztzeit o presente eterno que escabulla cualquier comprensión de la revolución como telos. Más bien, revela el Estado que no es Estado no como un estado de naturaleza - esa comprensión tan desinformada de la anarquía como la que expresó Hobbes en Leviatán frente a las culturas sin o fuera de la historia [without history] ${ }^{9}$ - sino como una condición siempre al borde de la institucionalización, siempre tambaleándose entre el poder y el contrapoder.

Estas cuestiones, por otra parte, reflejan no sólo la posibilidad de existencia y sostenimiento de un Estado que no es Estado sino también los tropiezos y obstáculos en el proceso de la descolonización y la complejidad de volver al pasado caminando hacia el futuro. Parecería, en el contexto de la Zona Liberada, que ha sido relativamente fácil expulsar a los q'aras del territorio y más complicado, al decir de Fausto Reinaga, "sacar a Cristo y a Marx de la cabeza de los hombres" (82). Con el afán de "reeducar" a los qullasuyanos en la epistemología y espiritualidad propiamente andinas, el gremio de amawt'as se encarga de extirpar el cristianismo, respondiendo a las evidencias recurrentes de cierto "criptocristianismo" presente en la Zona con un mecanismo parecido al lavado de cerebro asociado con la homogeneización ideológica del socialismo soviético o incluso del fascismo - con la diferencia fundamental, sin embargo, de que no se trata de una eliminación del adversario como fortalecimiento del poder hegemónico, sino de una

8 "[H]ay mucha envidia. Eso no se lo llevaron los q'aras al irse", observa Saturnina (267).

9 Véase Ticona (139-140) para una discusión de esta perspectiva de Hobbes, y Rabasa (13-16) sobre el significado doble de la expresión "without history". 
tentativa de descolonización mental necesaria para la proliferación de la diferencia y la restitución de saberes y conocimientos subyugados.

De ahí que el Willkaqamani, supremo sacerdote, muere a manos del Tata Santiago, quien lo persigue y lo atormenta hasta que finalmente se lo lleva. Siguiendo el consejo tramposo de la Satuka, el Willkaqamani se persigna, sólo para ser llevado por el santo en su caballo blanco y morir en el proceso: "Se persignó, y con eso anunció que era dellos, y le llevaron" (274). Si bien Santiago se identificó con Illapa desde la Conquista y se confundió con este dios del trueno, ${ }^{10}$ la figura que atormenta al Willkaqamani en este caso sería el santo y no el dios andino. Así, cuando intenta apelar a Illapa no le resulta, como explica la Satuka a Feliciana:

-¿¿Pero Santiago es Illapa, ¿no?

-O al Illapa le han convertido en Santiago. Pero esto no era de Illapa, pues, era de Tata Santiago.

- No te entiendo cuando te pones a hablar de teología.

-Son misterios de la fe. El se había dao cuenta, pero, que no estaba resultando, que tenía que buscar a Tata Santiago siempre (271).

Santiago, de esta forma, desempeña el papel de un espíritu subyugado (ahora por el anticristianismo amawt'ista) que vuelve como guerrillero de guerrillas para desestabilizar la autoridad del Willkaqamani: "Tata Santiago ha estado ya tiempo en la clandestinidad, sabe cómo hacer las cosas sin que le rastreen. Se revela sólo cuando ya no hay remedio" explica Saturnina (264). Es irónico, por supuesto, que el santo conocido como Santiago Mataindios - por ser el Patrón cuyo nombre invocaban los españoles al lanzarse contra los indios - ahora mate a un sacerdote indígena, si esta muerte sirve para acortar el creciente poder de esta figura y remitir la carga espiritual a otro. Pero al mismo tiempo, no deja de interesar el hecho de que esta atenuación se logre mediante la insurgencia del cristianismo sincrético ahora subalternizado a la espiritualidad precolombina institucionalizada de los amawt'as.

10 "Santiago quedó identificado con Illapa en: 'el milagro del Sunturhuasi' (hoy Catedral), cuando en Cuzco, al grito de 'Santiago' y bajo una tormenta, los españoles vencieron a las tropas de Manco II (1536) desde Sacsahuaman" (Gisbert 76). 
No es tan fácil, al parecer, "enterrar" el mundo colonial o "expulsarlo" del territorio, como pide Fanon. ${ }^{11}$ ¿Cómo distinguir, en este caso, entre creencias aymaras y europeas si estas dos civilizaciones han vivido en contacto por más de medio milenio? La respuesta parecería plantear que el cristianismo también es -o puede ser - indígena, que la evangelización resultó no sólo en la subyugación violenta de la espiritualidad indígena al código de la religión monista sino también, insólitamente, en la creación de nuevos espíritus y energías que complementan y refuerzan la compleja gama del panteón andino. Es la religión popular, en todo caso, que sigue irrumpiendo, desestabilizando el dogma de la religión oficial o del código espiritual dominante. De ahí que, más que buscar eliminar completamente los rastros de la cultura europea dentro de la Zona, el sistema del ayllu ha sabido instrumentalizarlos dentro de sí mismo, ya que la oposición interna de estos elementos en relación al poder aymara sirven finalmente para reforzar el sistema de organización social propia mediante su constante desestabilización, en lugar de debilitar el sentido de autonomía de ese sistema.

En referencia a la comprensión andina del poder, Esteban Ticona observa que ésta no es asimilable a una teoría universalista (es decir, occidental), aun a un marco tan abarcador como el de Foucault, que enfatiza la circulación del poder fuera de los ámbitos de la política tradicional de gobierno, partidos y Estado:

¿Por qué pensar que el concepto de poder de Foucault es universal? En muchas sociedades y en especial en las andinas indígenas y campesinas, no existe el concepto de poder en el sentido foucaultiano. No es que estas sociedades hayan superado las formas de dominación interna, sino que el poder no está conectado a la dominación absoluta y a la eliminación total del adversario (147).

$\mathrm{Si}$ el argumento es que el poder sigue existiendo en todos los lugares, la conclusión no debería ser que una sociedad más igualitaria es imposible sino, al contrario, que existen otras formas posibles de instrumentalizar y organizar el poder -e inclusive la envidia, la ambición y el antagonismo social- dentro de la sociedad, de manera tal que no termine respaldando estructuras nefastas como el colonialismo.

11 “Dislocar al mundo colonial no significa que después de la abolición de las fronteras se arreglará la comunicación entre las dos zonas. Destruir el mundo colonial es, ni más ni menos, abolir una zona, enterrarla en lo más profundo de la tierra o expulsarla del territorio (35). 


\section{"Esas babeadas del chachawarmi"}

La concepción de poder que subyace al sistema del ayllu, entonces, corresponde a una lógica de reciprocidad cultural que articula un equilibrio entre elementos opuestos, buscando siempre evitar que un elemento domine sobre los otros. Como horizonte de posibilidad anárquico, sin embargo, este ideal encuentra sus limitaciones dentro del mismo ayllu, donde inconsistencias internas ocasionadas por dinámicas de poder no suficientemente equilibradas obstaculizan el funcionamiento del código sociopolítico. Este punto nos lleva al otro eje fundamental del Comando Flora Tristán: esto es, su lucha contra el patriarcalismo, no sólo en la actitud paternalista de occidente - la cual interpretaría el cambio político en América Latina-Abya Yala como únicamente posible mediante la tutoría de los intelectuales de fuera - sino también en la falta de correspondencia dentro de la comunidad entre sus miembros masculinos y femeninos. Así se entiende la interpenetración de patriarcalismo e imperialismo como dos gestos del mismo ímpetu subalternizador: "El lema del Flora Tristán en el fondo es el separatismo doble - nos cuenta Saturnina-, fuera q'aras y fuera hombres" (101).

La idea, sin embargo, no es que la desigualdad de género dentro del ayllu indique una falla fundamental en el diseño del mismo, sino que el ideal de chachawarmi (reciprocidad entre hombre y mujer, masculino y femenino) que profesa la ideología del ayllu se limita al plano discursivo y no se concreta dentro de la comunidad real. "Nos cagamos en esas babeadas de chachawarmi, qué hay de complementariedad si al fin los hombres siguen copando los puestos directivos", protesta Saturnina: "[...] en eso entraban las anarquistas diciendo abajo el trono y punto. Igual criticaban su sistema democrático, unas cuantas diputadas y de vez en cuando una ministra no afecta el fondo del sistema masculinista. Buscamos otro modelo, decían, no el Nuevo Poder sino el contra-poder" (101). El problema concreto en el caso del Qullasuyu hipotético del futuro es que los puestos de autoridad siguen siendo ocupados, casi sin excepción, por hombres:

¿Cuántas mujeres hay en el Consejo de Amawt'as? ¿Cuántas mujeres ch'amakanis hay, amawt'as de provincia siquiera? Te dicen que te ha sido dado para qulliri, qaquri, recetar yerbas, masajear a las embarazadas y chau. Y después aunque te acepten para niveles superiores, tienes que practicar según lo que dicen ellos. Dicen que no tienen nada que ver con la Iglesia de los curas pero más bien se han puesto sus zapatos desos (187). 
De este modo, Satuka demuestra la necesidad de des-jerarquizar no sólo la relación entre el mundo occidental y el aymara a gran escala geopolítica, sino también de des-tejer ciertas desigualdades dentro del ayllu mismo y de empujar a la comunidad a enfrentarse a las implicaciones de su propia ideología cultural. Tal como propone la Comunidad Mujeres Creando Comunidad en la Bolivia actual, el Flora Tristán deconstruye la noción de chachawarmi en la ex Bolivia del 2086, demostrando la falsedad de la misma y cierta afinidad con las prácticas represoras y paternalistas de los curas católicos (neo)coloniales. Siguiendo una lógica idéntica a la de Saturnina, Julieta Paredes anota, en un libro reciente, que "Nuestra propuesta es la reconceptualización del par complementario, despojarlo de su machismo, de su racismo y su clasismo, replantearlo en mujer-hombre, warmi-chacha que recupera el par complementario horizontal, sin jerarquías, armónico y recíproco, par de presencia, existencia, representación y decisión" (30).

Para Zibechi, esta conciencia que se adquiere sobre la marginalidad de género va de la mano con las luchas políticas más amplias del pueblo indígena:

La autonomía busca resolver la cuestión del poder, que es la causa de la exclusión y la marginalidad de los pueblos indios. [...] Sin embargo, como lo demuestra la experiencia zapatista en Chiapas, la autonomía communal, municipal y regional no sólo busca cambios en las relaciones de poder hacia fuera, sino también en el interior de los pueblos indios. Así, las mujeres zapatistas no separan la cuestión de la autonomía de la cuestión de género, ya que conciben la autonomía como una nueva relación, integral, que abarca todos los aspectos de la vida, tanto los externos como los internos. Las desigualdades socioeconómicas y culturales, que no habían sido cuestionadas o eran vistas como inevitables, 'empezaron a ser percibidas por las activistas indígenas como resultado de la discriminación, de la exclusion, de su status de minoría política' (Zibechi 175-176).

La implicación es que cada proceso de transformación cultural, cada pachakuti, va revelando nuevas capas de poder y desatando respuestas de contra-poder en una quimera infinita. La implicación, sin embargo, no es la futilidad de la lucha sino todo lo contrario: es la circularidad de la historia en pachas consecutivas y divergentes que permite entender que todo, con tiempo, pasará. Nos remite, como señala González León, a la posibilidad de otro pachakuti donde se revertiría no sólo el orden de

\footnotetext{
${ }^{12}$ La última parte de esta cita viene de Héctor Díaz Polanco, México diverso 115.
} 
dominación neocolonial sino también el patriarcalismo que opera dentro del ayllu: "Otro Pachakuti, en el que las mujeres quedan arriba, podría ser posible". De esta forma, Spedding utiliza la forma de la "historia oral del futuro" y la ubicación temporal del relato en el futuro para empujar la reflexión incluso más allá de la disolución del Estado e imaginar una suerte de violencia pura revolucionaria (estilo Benjamin) encarnada en la lucha feminista-anarquista de Saturnina y el Flora Tristán. "Somos la revolución permanente", declara la Satuka (82); y la disolución del Estado, más que punto de llegada o telos revolucionario, serviría como punto de partida para otras transformaciones posibles.

En este sentido la mirada anti-utópica de la novela, que quizás podríamos calificar de realista o pragmática, es fundamentalmente crítica y constructiva: en lugar de idealizar una cultura no-occidental bajo el estereotipo del "buen salvaje" o el "ser de la naturaleza" que Hegel asociaba con las sociedades sin Estado, o propagar fantasías "pachamámicas" e idealizadas, demuestra que la cultura aymara tiene sus propias manifestaciones y grados de poder, sólo que operan según una lógica distinta a la civilización occidental. No simplemente alaba el "Estado que no es Estado" y la forma de convivencia aymara como una meta final; más bien - $-\mathrm{y}$ para bien - los instala como una realidad alcanzada con otras metas y desafíos pendientes. La novela tiene el efecto, entonces, de volver nuestra mirada a la actualidad, a nuestro propio pasado-futuridad para comprender la incidencia de estructuras de poder inmanentes en el Estado pero también anteriores $-y$ posiblemente posteriores - a él. No sólo hace falta la descolonización política e ideológica y la reinstauración de un orden aymara precolombino, sino también la reconsideración de la propia cultura aymara a la luz de la soberanía de la mujer, o incluso una descolonización de género, como propone la Comunidad Mujeres Creando Comunidad. Este proceso, como señala Paredes, indica la necesidad de "reconocer que las relaciones injustas entre hombres y mujeres aquí en nuestro país, también se dieron antes de la colonia y no que sólo es una herencia colonial. [...] Descolonizar el género, en este sentido, significa recuperar la memoria de las luchas de nuestras tatarabuelas contra un patriarcado que se instauró antes de la invasión colonial" (24). Lo que la novela de Spedding nos demuestra, finalmente, es que el proceso de descolonización va más allá de la política estatal y la dominación de una cultura por otra, ya que implica repensar estructuras de dominación dentro de la comunidad misma. La Liberación de la ex Bolivia de la influencia europea y la herencia estatista de la colonialidad, en otras palabras, no es poco, pero tampoco es todo. 


\section{Bibliografía citada}

ALFARO, Raquel. 2010. Reseña de De cuando en cuando Saturnina (Saturnina from time to time). Una historia oral del futuro, por Alison Spedding. Bolivian Studies Journal/ Revista de Estudios Bolivianos 15-17 (20082010): 346-349.

BENJAMIN, Walter. 2005. Tesis sobre la historia y otros fragmentos. Bolívar Echevarría, ed. y trad. México: Clio.

DÍAZ POLANCO, Héctor y Consuelo Sánchez. 2002. México diverso: el debate por la autonomía. México: Siglo Veintiuno.

FANON, Frantz. 2003 [1961] Los condenados de la tierra. Julieta Campos, trad. México: Fondo de Cultura Económica.

GISBERT, Teresa. 1999. El paraíso de los pájaros parlantes. La imagen del otro en la cultura andina. La Paz: Plural/Universidad Nuestra Señora de La Paz.

GONZÁLEZ LEÓN, Anabel. 2006. “Después del Pachakuti. Tiempo mitológico aymara y ciencia ficción”. I Congreso Internacional Mitos Prehispánicos en la Literatura Latinoamericana. Barcelona.

[http://www.ecdotica.com/2007/05/17/despues-del-pachakutitiempo-mitologico-aymara-y-ciencia-ficcion/] página descargada el 14 de noviembre, 2011.

GUHA, Ranajit. 1996. "The Small Voice of History." Subaltern Studies. Writings on South Asian History and Society. Vol 9. Shahid Amin and Dipesh Chakrabarty, eds. Delhi: Oxford University Press. 1-12.

PAREDES, Julieta. 2010. Hilando fino desde el feminismo comunitario. La Paz: Comunidad Mujeres Creando Comunidad.

RABASA, José. 2010. Without History: Subaltern Studies, the Zapatista Insurgency, and the Specter of History. Pittsburgh, PA: University of Pittsburgh Press.

REINAGA, Fausto. 1978. Indianidad. La Paz: Partido Indio de Bolivia.

RIVERA CUSICANQUI, Silvia. 1993. "La raíz: colonizadores y colonizados." Violencias encubiertas en Bolivia. Tomo 1: Cultura y política. Silvia Rivera Cusicanqui y Raúl Barrios Morón, eds. La Paz: CIPCA/Aruwiyiri. 27-139.

SPEDDING PALLET, Alison. 2004. De cuando en cuando Saturnina (Saturnina from time to time). Una historia oral del futuro. La Paz: Editorial Mama Huaco.

TICONA Alejo, Esteban. 2010. Saberes, conocimientos y prácticas anticoloniales del pueblo aymara-quechua en Bolivia. La Paz: Plural. 
ZIBECHI, Raúl. 2006. Dispersar el poder: los movimientos como poderes antiestatales. Buenos Aires: Tinta Limón.

\section{(c) BY-NC-ND This work is licensed under a Creative Commons Attribution- Noncommercial-No Derivative Works 3.0 United States License. \\ ULLS D-Serle Unis journal is published by the University Library System of the Program, and is cosponsored by the University of Pittsburgh Press.}

Bolivian Studies Journal /Revista de Estudios Bolivianos

http://bsj.pitt.edu

Vol. 18 • 2011 • doi: 10.5195/bsj.2011.48 • ISSN 1074-2247 (print) • ISSN 2156-5163 (online) 